\title{
Exploration on the Innovative Mode of Automobile Service Specialty Training under the Background of New College Entrance Examination
}

\author{
Shuqing Guo ${ }^{1, a}$, Shuo Huang ${ }^{1, b}$ and Lufei $\mathrm{Wu}^{1, \mathrm{c}}$ \\ ${ }^{1}$ College of Transportion and Building Engerring, Beihua University, Jilin,jilin city,China \\ a472620227@qq.com, b154767013@qq.com, '1050532634@qq.com
}

\begin{abstract}
Keywords: New college entrance examination mode; Automotive service engineering; "1+2+1" collaborative training mode; Practical ability
\end{abstract}

\begin{abstract}
It will bring us opportunities for the professional development of colleges and universities thanks to the reformation of college entrance examination mode. The " $1+2+1$ " college enterprise mdoe could be put forward through the investigation of the professionals needs of the car services of society and enterprise, and contrast of the conventional talent training model, which is training depending on the school and enterprise. It is very important to the cultivation of the talent quality and improvment of practical abilities.
\end{abstract}

\section{Introduction}

The model about the college entrance examination is changing in China, which will transform school grade admission into a professional admission, so the professional ranking is particularly important, while obtaining high-quality students would rely on professional ranking, therefore the innovative training model is the key to improve the professional rankings.

For a long time, the examination-oriented education has been adopted in our country, resulting in "high score low energy" and pedant to a large number of students[1]. The main task of higher education is to provide the support of intellectual and human resource for knowledge and technological innovation.

In recent years, the senior technical personnel required automotive services will be put forward new requirements, with the change of car's constructure and the controlled equipment. At the same time it bring the automotive service enterprises huge development space with the amout of the car. At present, colleges and universities focus only on the teaching of students 'theoretical knowledge, ignoring the cultivation of students' practical skills, leading to the poor ability of the automobile service professionals trained in the school, and finally it has a gap with the enterprise demands. In order to strengthen the students' practical abilities and reduce the time to adapt to the enterprise, and make the students adapt to the job quickly, so it will be created the professional characteristics of automotive services by reforming the trained model existing automotive service engineering professionals.

\section{The Determination of Personnel Training Objectives and Ability and Quality}

The Personnel Training Objectives of the Automobile Service Engineering Professional. The professional training objectives is senior engineering and technical personnel, with a good ideological and moral cultivation and cultural cultivation, rich in modern scientific and innovative awareness, with a solid automotive products and technology base, the necessary knowledge of automotive service theory, with a certain degree of modern information technology and network technology knowledge and skills, with "will be able to operate, good service,"the ability to quality, able to engage in automotive product design services[2], automotive production services, car modification services, automotive marketing services and automotive testing and maintenance services in areas.

Knowledge, Ability and Quality of Automotive Service Engineering Professionals. A variety of knowledge, ability and quality requirements must be clear about training personnel during constructing the personnel training program system. Automotive service engineering is based on the 
basic theory and expertise of automotive technology and the use of services, mainly to study the value of the realization of a reasonable way of car merchandise, The appropriate means of ensuring the value of the use of the vehicle and the legal procedures for protecting the legitimate rights and interests of the consumer. In ability requirements, first the professional application of talent must have a stronger engineering practice ability, that is, modern car detection diagnosis and maintenance, as well as automotive marketing, insurance claims, information consultation, status evaluation and the vehicle management, etc. But also requires a stronger ability to innovate, in view of foreign language and computer is an important learning tool, it should have a stronger applying abilities at foreign language and computer in the professionals.

In terms of quality, it needs not only to have a higher professional quality, but also a certain non-professional quality at the professional application of talent. Non-professional quality often affects the individual's personal responsibility, psychological quality and will quality, etc., it is the individual's response of the overall quality. According to the characteristics of this specialty, the four qualities are required, them are: humanistic quality, ideological and moral quality, professional quality and physical and mental quality, which the professionals should have. In addition, the level of the quality of the basic knowledge of the project, humanities and social knowledge and cross knowledge[3-5]. The higher the quality, the greater the possibility of cross-integration of knowledge, the ability to be stronger. In order to build a talent training program system, the knowledge, ability and quality should be clear to the automotive service engineering professionals.

An Analysis of the Current Situation of Personnel Training Mode in Automobile Service Engineering. Pay close attention to enterprise development, it can achieve a seamless docking to talent training specifications and business needs, through coordinating various positions can help contribute to the positioning of automotive service professionals, the professional positioning in the industrial chain as shown in fig. 1: as can be seen from the figure, car service professionals will be existing throughout the car cycle[6,7].
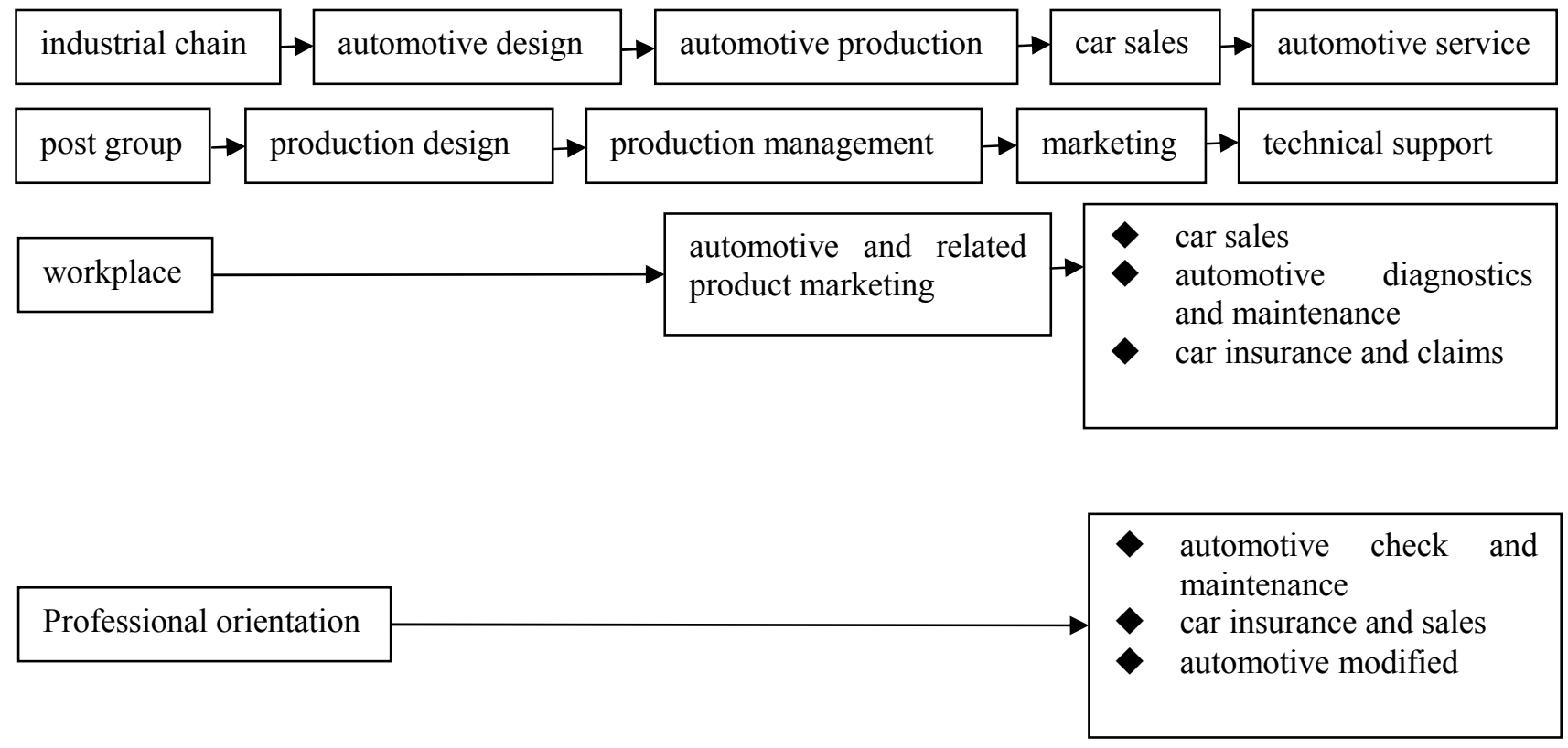

Figure 1. The position of automobile service engineering specialty in industry chain

In order to meet the wide caliber employment needs, three directions is located in car service engineering professional in our school: Car marketing and insurance, automotive after-sales service and car modification services. It focuses on the integration with social development in course settings, such as the addition of "second-hand car evaluation", "car vanished technology" and other courses; in order to improve the practice of students' skills, as soon as possible to adapt to the job, the training which includes the "car testing and maintenance" and "automotive electrical and electronic control system" is increased from the original 1 week to 4 weeks. Personnel training 
model has yet to be innovated when we are facing with the new college entrance examination system and the needs of enterprises of high-end complex talents.

\section{Construction of " $1+2+1$ " Innovation Mode for Enterprise and Enterprise Collaborative Talents Training}

It must promote the school-enterprise cooperation personnel training model, basing on the serve and employment-oriented, and emphasize the cultivation of practical ability, strengthen social services which our school, deepen the integration of school and enterprise cooperation, update the teaching philosophy, relying on industry and enterprise advantages, make full use of teaching resources, establish school-enterprise depth of cooperation and closely connection, complementary advantages and common development of the cooperation mechanism, finally lead to achieve "win-win" purposes, thus improve the teaching level and personnel training quality of Automobile service engineering, and hard to create a new situation of school - enterprise cooperation.

And it explore and build actively " $1+2+1$ " cultivation model of school and enterprises, as shown in fig. 2, that is: 1 year basic knowledge study, 2 years of professional knowledge study and last 1 year to business training / internship.

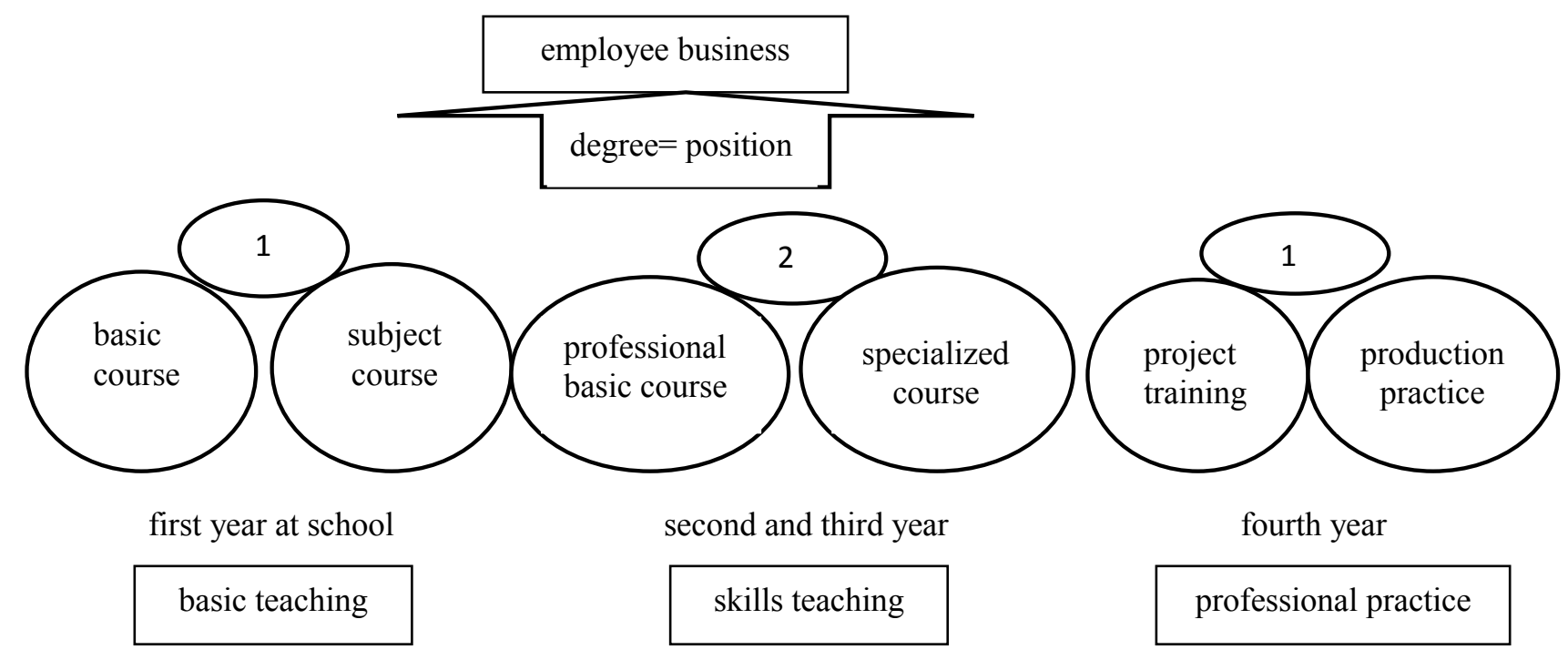

Figure 2. Personnel training of automobile service engineering talents " $1+2+1$ " mode

" $1+2+1 "$ model is the students learning in the school from 4 years to 3 years, then that should be adjusted accordingly to the basic class hours and courses, which must be related to the future job due to the cooperation with enterprises, so that personnel can be trained to be practical first-line; All the professional courses should complete during the 2th and 3 th year. The professional course content will be close to the practical application because of this school mode, and which closely related to social development[8,9]. The professional practice will complete in the last year, project training can be done at school or to participate the enterprise, finally it is the production practice.

"Our platforms, two Modules" of the Curriculum Architecture on Automotive Service Engineering Professional. It should take into account the various courses of teaching content, from shallow to deep, step by step to avoid repeatability on the basic of "broadening knowledge, ensuring the foundation, improving the quality, focusing on the application" principle. According to the spirit of "solid foundation, fine professional, strong skills, good innovation" talent training ideas, in accordance with the goal of diversified personnel training, serves the students as spirit, expand and strengthen practical skills, focus on the implementation of innovative education, reform traditional courses model, course content, teaching methods and means[10]. We will build the curriculum system of "four platforms, two modules". Four platform refer to the general education curriculum platform, the basic curriculum platform, professional direction curriculum platform, integrated 
practice course platform, and two modules refer to "innovation and quality development module" and "practical ability module". Students can choose different modules to meet the needs of students personalized development, and create conditions for individualized students. Basic type reflects in the required class, improvement in the elective class, innovation in the extracurricular from the basic type to the improved type to the innovative. In order to adapt to the variety and timeliness of social needs, it will reform the fixed teaching content, set up flexible teaching modules. Not only to meet the needs of personalized personnel training, but also to protect the needs of the community-oriented personnel training objectives of the smooth realization. It will improve the teaching content of the course and the social needs of the adaptability and the development of automotive services to the advanced nature.

The "Four Combined" Teaching Methods and Teaching Means. The traditional inculeating way of teaching and "teachers one speech" should be changed, new methods will be used such as multimedia, micro-class, Mu-class and other modern technical means, it combines intensive teaching, giving direction, inducing thought and exploration into one. In the classroom, the actual case should be taken as the main line to improve the students' thinking, analysis and problem solving, the purpose is fully to mobilize the enthusiasm of learning, to promote the improvement of student capacity. It will build "four combined" teaching mode depending on "production and learning" combination greatly, and by the use of the three teaching platform:, classroom teaching, network teaching and after-school discussion. That is, the combination of tangible classroom and network classroom, the combination of classroom teaching and extracurricular tutoring, teacher teaching and teacher and student research combined with intensive reading materials and extensive reading of the expansion of information combined. Here is application materials which writes with the enterprise together.

Practice the Skills as the Core, Cultivate "Double Teacher" as the Goal. The school teachers should take the training for enterprise staff and continuing education by use of themselves' resources. In return, school teachers participate in enterprise R \& D projects and technical services to improve teachers' practical ability. At the same time it establishes a good support system, mutual benefit, mutual support, to obtain the support and help of the school equipment and facilities.

It trains university teachers regularly and improve effectively their practical teaching ability and professional level through the systematic content design, customized training services.

In addition, we'll hire excellent technical staff with rich practical experience coming from the enterprises as part-time instructor. An effective mechanism will continue to develop by building teachers community. Then the "double tutor" system can be practiced fully for the undergraduate, and give students lectures regularly by employing celebrity of the business, which communicate to students. Also it send students to enterprises regularly to visit, practice, then to achieve seamless docking between school and employer's, to achieve the collaboration and innovative personnel training.

\section{Construction of "Full-Level, Hierarchical, Progressive, Modular" Collaborative Training of the Practical Teaching System}

I will solve the ways and means of training the school personnel by use of enterprise advantages, then to drive teachers and students training with projects to make up for the lag caused education and the old knowledge.

Relying on the innovation practice campus base and enterprise training platform of automotive service engineering professional, driven by interest, the project and all various of competition as the carrier, which will carry out collaborative training of "self-learning and expert guidance combined", full-time, hierarchical, progressive, modular.

Paying attention to the coherence and systematicity of practical teaching, it should promote the systematism of the practical teaching through the reasonable practice teaching norms and assessment methods. To broaden the practical teaching of automotive service engineering, the experimental will be independent from the theoretical, and to increase it's quantity appropriately; and to increase the comprehensive, design experimental content combined with practical 
applications. Make full use of laboratory resources to exercise students the practical ability such as: actual operating, analysis, and to deal with problems; It mainly includes three levels that is classroom practice teaching, professional skill practice and enterprise practice teaching in practice process. Practice teaching modules covers experimental teaching, professional skills training, internships, trainees, and research training.

The training system is derived from the practice, from the enterprise, and the training program has the integrity, the mobility characteristic. Students in the training base can understand and adapt to the business environment, they'll accumulate actual experience to realize seamless docking from graduation to work.

\section{To establish a "Three in one" Multi-Angle Evaluation System}

It will establish the learning effect evaluation system of "student evaluation, teacher evaluation, social evaluation".

It will change the teacher's absolute dominant position by the way of evaluation, and strengthen students' mutual assessment and team co-supervision, thus improve the enthusiasm and enthusiasm of students to participate, cultivate team awareness, especially the score assessment system is taken to participate extracurricular of the practice. Introducing enterprise guidance teacher scoring mechanism, the grade is made by the enterprise management and technical guidance staff according to the actual performance of students during the enterprise. The evaluation method is agreed by the school and the enterprise. The result of the scoring is directly proportionally included in the general term of the semester.

\section{Summary}

On the basis of the existing training program of automobile service engineering professionals, the author further explores the innovation mode of " $1+2+1$ " talent cultivation innovation model, which is demonstrate from the theoretical and practical ability to cultivate, with a certain practical. This model will achieve good results in the training of students' social ability, practical ability, professional quality, employability, etc. Practice has proved that this is an effective way to strengthen engineering practice, to improve professional ability and social awareness, and cultivate high-level specialized technical talents. In the future, we need to further explore, practice and continue to improve according to the actual problems and operation methods to construct a more scientific and reasonable training model with advanced application and adapting to social needs talents for automobile service engineering.

\section{References}

[1] S.F.Xiao, Z.W.Deng and Q.Hu: China's Modern Educational Equipment, Vol. 25 (2011) No.18, p.49.( In Chinese)

[2] Information on http://www.doc88.com/p-1317548333090.html

[3] R.J.Lei: Journal of Higher Educa, Vol. 2 (2017) No.5, p.109.( In Chinese)

[4] X.Ning, J.G.Yao: Journal of Henan Institute of Science and Technology, Vol. 8 (2015) No.6, p.30.( In Chinese)

[5] X.P.Zhang and Z.Z.Fan: Information Construction, Vol. 6 (2016) No.2, p.347. (In Chinese)

[6] C.L.Liu: China Education Technology \& Equipment, Vol. 1 (2017) No.4, p.148. (In Chinese)

[7] X.L.Xu and Y.Zhang: Guangxi Education, Vol. 2 (2015) No.27, p.59. (In Chinese)

[8] L.M.Zheng, J.H.Wen and W.J.Gao: Journal of Liaoning University of Technology, Vol. 17 (2015) No.4, p.129.( In Chinese)

[9] X.M.Fu: Education Teaching Forum, Vol. 7 (2017) No.7, p.153. (In Chinese)

[10] Information on http://baike.baidu.com/lin 